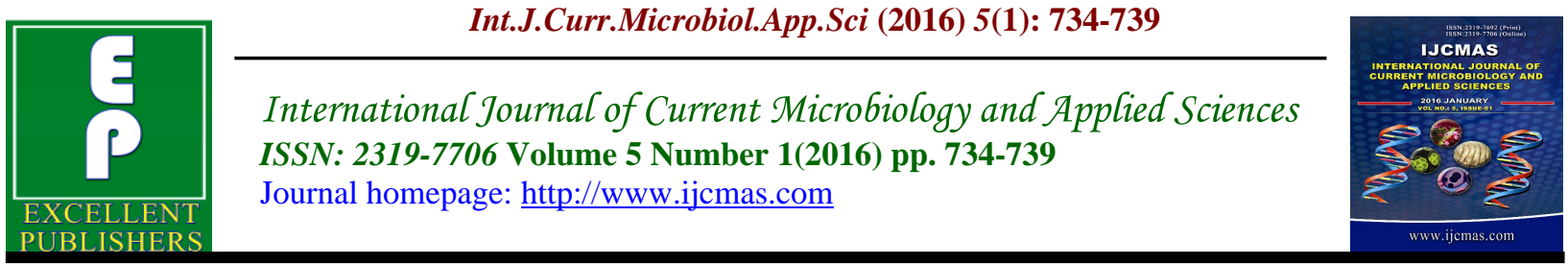

Original Research Article

hittp: ///dx.doi.org/10.20546/ijcmas.2016.501.074

\title{
IBA Induced Rooting Characteristics in Marathi Moggu Stem Cuttings: Evaluation Using SVI Concept
}

\author{
Justin R. Nayagam* \\ Department of Botany, Union Christian College, Aluva, Kerala, India, 683102 \\ (Affiliated to Mahatma Gandhi University, Kottayam) Kerala, South India \\ *Corresponding author
}

\begin{abstract}
A B S T R A C T
Keywords

Stem cuttings, Sprouting value index,

Bombax ceiba, Rooting media

Article Info

Accepted:

25 December 2015

Available Online:

10 January 2016

Rooting ability in IBA induced stem cuttings in vegetative regeneration experiments largely depends on various parameters, which has been established using SVI (sprouting value index), a mathematical approach. Marathi-moggu the Bombax ceiba tree is a medicinal and avenue tree species of tropical India that has known to have poor regeneration through seeds and hence in the present study stem cuttings of saplings were used to generate clonal plant propagules. Field studies were carried out using three rooting medium at a location in Central Kerala, Peninsular India, for one year at four months regular interval. Three IBA (Indole 3butyric acid) concentrations 300 ppm, 500 ppm and 1000 ppm IBA, have been used and the data obtained was evaluated with SVI (sprouting value index) method in order to evaluate the suitable medium, which gives maximum results. The control cuttings do not recorded rooting. The results obtained indicate high SVI (sprouting value index), when stem root cuttings planted in root trainers with coir pith compost (RTCP) for all the three concentration of IBA applied. Sprouting percentage was increased and the delay in completion of sprouting/rooting initiation decreased by the use of IBA treatment.
\end{abstract}

\section{Introduction}

Plant propagation has a global effect, as it is a fundamental occupation of human kind and its discovery dates back to the origin of civilization and ornamental gardening attained high level during the period between 500 B.C to A.D. 1000(Harlan, 1992; Solbrig and Solbrig, 1994). The vegetative propagation of herbaceous plants can be performed easily as many of them produces bulbs, rhizomes, corms, tubers, offsets, suckers and stolons which are natural vegetative propagating structures. But vegetative propagation in tree species is a difficult process and it is attained through hormone application mostly in stem cuttings, which eventually initiates adventitious root and shoots (Davies et al., 1994; Macdonald, 1986; Ritchie, 1994). Again, there are several mathematical expressions and explanations to measure seed germinationand viability in sexually reproducing plants (Czabator, 1962; Nicols 
and Heydecker,1968; Brown and Mayer, 1998; Bewley and Black, 1994; Santana and Ranal, 2004)but mathematical expressions for determining efficiency of vegetative planting material or for clonal propagation is scanty. The data obtained through the present investigation are being interpreted using sprouting value index (SVI) proposed by Nayagam (2015A).

Bombax ceiba has a geographical distribution in tropical Asia and New Guinea. In India it is distributed throughout the deciduous and evergreen forests (Chacko et al., 2002). In Kerala, it occurs in the evergreen and semi-evergreen forests up to $1200 \mathrm{~m}$, and also grown in homesteads (Sasidharan, 2004). Various parts of the tree such as leaves, stem bark, root of young plants, flowers, fruits and seeds have different medicinal uses in indigenous system of medicine (FRI, 1981). Since the flower bud of the species is widely used as a spicethe technology for regeneration fromcuttings is promising for the cultivation practice in future plantation programs.

\section{Materials and Methods}

\section{Specimen Collection and Conduct of Field Trials}

For the present investigation seeds were procured from mature trees in the Vengoor, Perumbavoor region and the regeneration experiments were conducted in T.C Joseph Memorial Botanical Garden, Department of Botany, Union Christian College, Aluva, (+10 7' 30.65", +76 $20^{\circ}$ ' 3.32") Ernakulam district, Kerala State, India and the stem cuttings were obtained from one year old saplings raised in the green house. All field trials were conducted in the plant nursery of T.C Joseph Memorial Botanical Garden.

For the sake of large scale planting material production in mechanized gardens, trials were conducted in $100 \mathrm{cc}$ root-trainer blocks (24 celled) using potting mixture (RTPM), root trainers with vermicompost (RTVC) and root trainers with coir pith (RTCP) as rooting medium.

\section{Experiment Design}

For all field trials, average of the three replicates during the months of February (P1), and June (P2), October (P3) during 2014were conducted in three different rooting medium such as root-trainers with potting mixture (RTPM), root trainers with vermi compost mixture (RTVC) and roottrainers with coir pith (RTCP). Stemcuttings with an average size of 7.5 to $10 \mathrm{~cm}$ were used. The sample size was kept twenty-four for each trials separately as the $100 \mathrm{cc}$ roottrainer block contains 24 cells. A non-auxin control and three Indole 3-butyric acid (IBA) concentrations were designed in this experiment with 300ppm, 500ppm and $1000 \mathrm{ppm}$ (parts per million) in order to detect the rooting/sprouting ability by quick dip method. A randomized complete block design was employed. After 45 days, the cuttings were evaluated for rooting/sprouting percentages, mortality percentage and viability percentage. The data obtained were subjected to one factor analysis, employing analysis of variance (ANOVA) and two-way ANOVA.

\section{Calculation of SVI}

In order to calculate sprouting value index (SVI), data regarding sprouting and successful rooting percentages (SP sprouting percentages), percentage of planting material with callus production but without rooting (CWR - callus without rooting), percentage of sound unsprouted propagule without callus production (SUP) (was determined by vertical cut test: 
planting material with more than three nodes living tissues was considered viable) was prepared. Viability percentage can be prepared using the formula $(\mathrm{VP}=\mathrm{SP}+$ $\mathrm{CWR}+\mathrm{SUP})$, peak value $(\mathrm{PV}=$ maximum mean sprouting recorded at any time during the test), final mean sprouting (final MDS = cumulative percentage of full sprouting at the end of the test divided by number of days to finish sprouting) were calculated. SVI index method developed through the present study is calculated by the equation, $\mathrm{SVI}=\mathrm{PV} * \mathrm{MDS}$.

\section{Results and Discussion}

Sprouting and rooting studies of stem cuttings were carried out in three different rooting medium during three seasons in a year (2011 - 2012 June, October and February), and the various attributes obtained are given in table 1 and table 2.

Table 1 gives the VP of stem cuttings in three concentrations used against the non auxin control whereas table 2 gives SVI in different concentrations (Fig. 1). Callus production as well as sprouting and rooting was very poor in control. VP obtained for IBA treated stem cuttings was highwith all the three concentrations used (ranging between $>79 \%$ to $94.64 \%$ ) in the rooting/sprouting medium RTVC and RTCP. With stem cuttings of Bombax ceiba,maximum SVI was obtained in 1000ppm treated cuttings. Maximum PV (11.11), maximum MDS final (1.91) and maximum SVI (21.22) was resulted in 1000 ppm treated cuttings in RTCP. Whereas lowest PV (4.17), lowest MDS final (1.42) and lowest SVI (5.92) was resulted in $300 \mathrm{ppm}$ treated cuttings in RTVC. The speed of completion of sprouting/rooting is found higher in RTCP than in RTVC.

The ANOVA results on callus formation and callus with root formation show significance at $1 \%$ level between concentrations of IBA.

The SVI studies worked out in the present study is a mathematical approach to determine the quality of rooting material, suitability of the medium used for rooting and the optimum concentration of IBA to be used.Production of elite genotypes of any plant species can be generated by vegetative method of propagation round the year. Successful propagation using stem cuttings has been reported by several studies in various plants, which uses stem cuttings, rhizomes or other vegetative parts (Sharma \& Aier, 1989; Rosier et al., 2004; Hartman et 1., 1997; Hambrick et al., 1991) but rooting of stem cuttings using tree species is very scanty and treatment of the results with mathematical approach is still few.

In field trials, all planting materials gave elite performance in RTCP planting medium. In the trials using 1000ppm IBA (Indole 3-butyric acid) treated cuttings also SVI was highest in RTCP (21.22). Significant differences in rooting were found between various rooting media was used, in sheanut cuttings (Akakpo et al., 2014). Sprouting percentage and speed of completion of sprouting/rooting initiation increased by the use of IBA treatment (Nayagam, 2015A). However, it is shown by other workers (Akakpo et al., 2014)that very high IBA concentration have negative effect in rooting. Comparing the CWR and SUP percentages one can also assess the defects in management practices, dormancy and the genotype of the cultivar.

Sprouting index value (SVI) proposed through the present study is a modified form of Germination value (GV), proposed by Czabator (1962)for seed germination studies. It is also suitable in field and nursery trials for vegetative propagation and IBA treated rooting of cuttings. 
Table.1 VP of IBA 1BA Treated Stem Cuttings of Bombax ceiba

\begin{tabular}{|c|c|c|c|c|c|}
\hline $\begin{array}{c}\text { IBA } \\
\text { Concentration }\end{array}$ & $\begin{array}{c}\text { Rooting } \\
\text { medium }\end{array}$ & CWR & SP & SUP & VP \\
\hline \multirow{5}{*}{$300 \mathrm{ppm}$} & RTPM & 5.55 & 0 & 4.17 & 9.72 \\
\cline { 2 - 6 } & RTVC & 6.94 & 63.89 & 8.33 & 79.16 \\
\cline { 2 - 6 } & RTCP & 11.11 & 66.86 & 16.67 & 94.64 \\
\hline \multirow{5}{*}{$500 \mathrm{ppm}$} & RTPM & 4.17 & 0 & 12.5 & 16.67 \\
\cline { 2 - 6 } & RTVC & 11.11 & 63.89 & 8.33 & 83.33 \\
\cline { 2 - 6 } & RTCP & 8.33 & 76.40 & 9.72 & 94.45 \\
\hline \multirow{5}{*}{$1000 \mathrm{ppm}$} & RTPM & 5.55 & 0 & 12.5 & 18.05 \\
\cline { 2 - 6 } & RTVC & 5.55 & 66.86 & 12.5 & 84.91 \\
\cline { 2 - 6 } & RTCP & 4.17 & 86.1 & 4.17 & 94.44 \\
\hline
\end{tabular}

Table.2 SVI Results of IBA Treated Stem Cuttings of Bombax ceiba

\begin{tabular}{|c|c|c|c|c|}
\hline $\begin{array}{c}\text { IBA } \\
\text { Concentration }\end{array}$ & $\begin{array}{c}\text { Rooting } \\
\text { medium }\end{array}$ & PV & MDS Final & SVI \\
\hline \multirow{3}{*}{$300 \mathrm{ppm}$} & RTVC & 4.17 & 1.42 & 5.92 \\
\cline { 2 - 5 } & RTCP & 12.5 & 1.49 & 18.63 \\
\hline \multirow{3}{*}{$500 \mathrm{ppm}$} & RTVC & 5.55 & 1.42 & 7.88 \\
\cline { 2 - 5 } & RTCP & 8.33 & 1.70 & 14.16 \\
\hline \multirow{3}{*}{$1000 \mathrm{ppm}$} & RTVC & 8.33 & 1.49 & 12.41 \\
\cline { 2 - 5 } & RTCP & 11.11 & 1.91 & 21.22 \\
\hline
\end{tabular}

Fig.1 Rooted Stem Cutting of Bombax ceiba



The incorporation of CWR (callus production without rooting) along with SUP (sound unsprouted propagule) in calculating VP (Viability percentage) is effective in finding the field oriented defects. SVI and VP is an integrated measure of planting material quality. The speed of sprouting/rooting ability along with the completeness of sprouting can also be determined vegetative planting materials. Suitable rooting media hold considerably high rooting ability (Nayagam, 2015B; Akakpo et al., 2014). 
Even though SVI for control were found zero, the VP for all the IBA treated trials are $>79 \%$ (table 1) which indicates that by using alternate methods like pretreatments and management practices, SVI can be increased. The internal physiology of the planting material may be the reason for the same. The change in planting material and IBA treatment used affects the rooting process as in the present study; SP was increased in higher concentration (1000ppm IBA). Methods for reducing CWR and SUP values can increase $\mathrm{SP}$ and the sample in rooting medium with least difference in SP and VP value will give maximum performance. Results of the rooting experiments showed that with very high IBA concentration in sheanut tree cuttings, rooting ability decreased (Akakpo et al., 2014)and hence three concentrations of IBA were used in the present experiment.

In conclusion, the present study focuses on regeneration of plantlets from stem cuttings of Bombax ceibaand the data obtained were interpreted using sprouting value index (SVI) to establish suitable vegetative planting material and suitable rooting medium through field trials. Trials conducted in different rooting medium reveal the sprouting efficiency and vigor in different medium. SVI is a statistically treated data, which is obviously a modification of germination value for seed germination proposed by Czabator (1962)the incorporation of CWR (callus production without rooting) along with SUP (sound unsprouted propagule) in calculating VP (Viability percentage) makes it suitable for vegetative cultivation practices and it interprets the quality of planting material, failure due to management practices and the selection of suitable rooting medium. This method of planting stock preparation is valuable in large-scale cultivation and much promising in producing quality clonal planting material production in economically important plants in future.

\section{Acknowledgement}

The author expresses his heartfelt gratitude to Dr. Thomas Philip, Principal and Prof. P. J. Aleyamma, Head of the Botany Department, Union Christian College, Aluva, for providing space to conduct field trials in the Dr. T.C Joseph Memorial Botanical Garden, Department of Botany, Union Christian College, Aluva. Thanks to Mr. Thomachen, Gardener, Dr. T.C Joseph Memorial Botanical Garden, Department of Botany, Union Christian College, Aluva, for maintaining the field specimens throughout the study period. Extending a word of thanks to Mr. Jabir who helped in statistical correlation.

\section{References}

Akakpo,D.B., Amissah, N., Yeboah, J., Blay, E., 2014. Effect of Indole 3Butyric Acid and Media Type on Adventitious Root Formation in Sheanut Tree (Vitellariaparadoxa C. F. Gaertn.) Stem Cuttings. American Journal of Plant Sciences, 5, 313-318

Bewley, J.D., Black, M., 1994. Seeds: physiology of development and germination. 2nd ed. Plenum Press, New York.

Brown, R.F., Mayer, D.G., 1988. Representing cumulative germination. 1. A critical analysis of single-value germination indices. Annals of Botany 61:117-125.

Chacko K, RC Pandalai, KK Seethalakshmi, C Mohanan, George Mathew and N Sasidharan (2002). Manual of Seeds of Forest Tress, Bamboos and Rattans in Kerala. KFRI Publicaton, KFRI, Peechi.

Czabator, F.J., 1962. Germination value: an 
index combining speed and completeness of pine seed germination. Forest Science 8:386396.

Davies, F. T., T.M. Davies, D.E. Kester, 1994. Commercial importance of adventitious rooting to horticulture. In T. M. Davis and B. E. Hassing, eds. Biology of adventitious rooting. Plenum Press, New York and London. pp.53-60.

FRI, 1981. Troup's The Silviculture of Indian Trees Vol.III. The Controller of Publications, Delhi.

Hambrick, C.E., Davies, F.T., Pemberton, H.B. 1991. Seasonal changes in carbohydrate/ nitrogen levels during field rooting of Rosa multi.ora 'Brooks 56' hardwood cuttings, Scientia Horticulturae,46: 137-146. 1991.

Harlan, J.R. 1992. Crops and man. $2^{\text {nd }}$ ed. Madison,Wia. Amer. Soc. Of Agron., Inc. Crop Science of America. America

Hartmann, H.T., Kester, D.E., Davies, F.T., Geneve, R.L. 1997. Plant propagation principles and practices. $6^{\text {th }}$ edition, Asoke K. Ghosh, Prentice-Hall of India. Private Limited, M-97, Connaught Circus, New Delhi - 110001.

MacDonald, A. B., 1986. Propagation facilities-past and present. Comb. Proc. Intl. Plant Prop. Soc. 35: 17075.

Nayagam, J. R., 2015A. Sprouting Value Index: A New Concept in Evaluation of Rooting of Cuttings.World Journal of Agricultural Research,
2015, Vol. 3, No. 4, 139-142.

Nayagam, J.R., 2015B. Plantation Technology for Seven Tropical Tree Species. LAP Lambert Academic Publishing, OmniScriptum GmbH \& Co. KG, Saarbrücken, Germany.

Nichols, M.A.and Heydecker, W., 1968. Two approaches to the study of germination data. Proceedings of the International Seed Testing Association 33:531-540.

Ritchie, G. A., 1994. Commercial application of adventitious rooting to forestry. In T. M. Davis and B. E. Haissing, eds. Biology of adventitious root formation. Plenum Press, New York and London. pp.3752.

Rosier, C.L., Frampton, J., Goldfarb, B., Blazich, F.A., Wise, F.C., 2004. Growth stage, auxin type, and concentration in uence rooting of stem cuttings of Fraser r. HortScience, 39: 1392-1396.

Santana, D.G., Ranal, M.A., 2004. Análise da germinação: um enfoque estatístico. Editora UnB, Brasília.

Sasidharan, N. 2004. Biodiversity documentation for Keralaa Part 6: Flowering Plants. KFRI publication, KFRI, Peechi, Thrissur.

Sharma, S.D., Aier, N.B., 1989. Seasonal rooting behaviour of cuttings of plum cultivars as in.uenced by IBA treatments. Scientia Horticulturae, 40: 297-303.

Solbrig, O.T., D.J Solbrig., 1994. So shall you reap. Farming and crops in human affairs. Island Press. Washington, D.C.

\section{How to cite this article:}

Justin R. Nayagam. 2016. IBA Induced Rooting Characteristics in Marathi Moggu Stem Cuttings: Evaluation Using SVI Concept. Int.J.Curr.Microbiol.App.Sci. 5(1): 734-739 http://dx.doi.org/10.20546/ijcmas.2016.501.074 